Relations industrielles

Industrial Relations

\title{
Pas de grève de sympathie
}

Volume 1, numéro 4, décembre 1945

URI : https://id.erudit.org/iderudit/1023918ar

DOI : https://doi.org/10.7202/1023918ar

Aller au sommaire du numéro

Éditeur(s)

Département des relations industrielles de l’Université Laval

\section{ISSN}

0034-379X (imprimé)

1703-8138 (numérique)

Découvrir la revue

Citer cet article

(1945). Pas de grève de sympathie. Relations industrielles / Industrial Relations,

1(4), 4-4. https://doi.org/10.7202/1023918ar

Tous droits réservés (C Département des relations industrielles de l’Université Laval, 1945
Ce document est protégé par la loi sur le droit d'auteur. L'utilisation des services d'Érudit (y compris la reproduction) est assujettie à sa politique d'utilisation que vous pouvez consulter en ligne.

https://apropos.erudit.org/fr/usagers/politique-dutilisation/ 


\section{PAS DE GRÈVE DE SYMPATHIE}

Depuis que dure la grève de Windsor, plusieurs rumeurs ont circulé dans la presse du pays, entre autres la possibilité d'une grève générale afin de prouver aux grandes compagnies la solidarité de la classe ouvrière. N'eât été la prudente modération de ses chefs, le mouvement syndical aurait commis un impair. Nous avons tous présente à la mémoire la triste expérience de Winnipeg en 1919. Déclencher une grève générale soulèverait actuellement la colère du public qui, tout en voyant d'un bon œil les progrès du syndicalisme au Canada, manifeste quelque nervosité. A ce sujet, la déclaration de M. Percy Bengough est significative. En effet, il a émis l'opinion que, dans les circonstances, décréter une grève générale serait une tactique dangereuse autant que stupide. Faisant allusion au fait que des milliers et des milliers de travailleurs affiliés à l'organisme dont il est le président étaient régis par des conventions collectives, M. Bengough estime que ces ouvriers n'ont pas l'intention de violer les engagements qu'ils ont contractés emvers leurs employeurs. A l'appui de sa thèse, il fait remarquer que si cette tactique était suivie dans toutes les usines à l'occasion d'un conflit particulier, les travailleurs seraient constamment en grève, car il y aura toujours un employeur hostile au syndicalisme dans une partie ou l'autre du Canada. Après avoir revendiqué justice pour les grévistes de Windsor, M. Bengough ajoute : " Mais lorsqu'ils auront obtenu satisfaction, nous ne pouvons admettre qu'immédiatement après avoir conclu cette entente de travail, ils la brisent tout de suite parce qu'il y aura un autre employeur hostile engagé dans un différend industriel dans une autre partie du Canada ". Le bon sens de M. Bengough a prévalu ainsi que la clairvoyance du Conseil exécutif du Congrès Canadien du Travail auquel sont affiliés les grévistes. En effet, à la grève de sympathie, on a substitué le versement d'une journée de salaire par tous les unionistes. Voilà qui est plus juste et plus réaliste. On sait que la C. T. C. C. s'est toujours opposée à la grève de sympathie. L'opinion des divers groupements syndicaux semble donc unanime sur ce point.

\section{STRUCTURE DU MINISTÈRE PROVINCIAL DU TRAVAIL}

Le ministère du Travail a été organisé comme département distinct de l'administration provinciale en 1931. Antérieurement, il faisait partie du ministère des Travaux publics. On peut désigner l'administration du ministère sous quatre titres principaux qui révèlent la nature des services que chaque section doit rendre au public. Ces sections sont :

\section{$1^{\circ}$ Relations industrielles}

Dans cette section, nous pouvons grouper les services suivants : a) la Commission du salaire minimum ; b) la Commission des relations ouvrières ; c) le Service de conciliation et d'arbitrage ; $d$ ) le Service des conventions collectives; $e$ ) le Service d'apprentissage ; f) le Service de placement provincial.

\section{$\mathscr{2}^{\circ}$ Sécurité}

Sous la rubrique "Sécurité des personnes et de la propriété " apparaissent les services suivants qui ont la responsabilité de mettre en vigueur les lois relevant de leur compétence : $a$ ) le Service d'inspection du travail et des édifices publics ; $b$ ) le Bureau des examinateurs des électriciens et le Service d'inspection des installations électriques; $c$ ) le Bureau des examinateurs des mécaniciens de machines fixes et le Service d'inspection des bouilloires; $d$ ) le Bureau des examinateurs des mécaniciens en tuyauterie.

\section{$3^{\circ}$ Assurances sociales}

On place, sous ce titre, la Commission des Accidents du Travail qui, pour toutes fins pratiques, administre une assurance mutuelle des employeurs de vingt-quatre classes d'industries diverses et la compensation des accidents de travail des employeurs de la cédule II qui portent eux-mêmes le risque des accidents. La Commission comprend maintenant un Service de réadaptation et une Clinique médicale spécialisée.

\section{$4^{\circ}$ Assistance sociale}

$\mathrm{Au}$ chapitre de l'assistance sociale, on relève la Commission des pensions de vieillesse, l'Office de l'assistance aux mères nécessiteuses et de l'Assistance aux aveugles. Ces organismes relèvent tous de l'autorité du Ministre du Travail.

Enfin, un Conseil supérieur du Travail formé de trente membres, dont huit représentant les employeurs, huit, les salaries, huit, les économistes et sociologues et six, le ministère du Travail et le ministère du Commerce et de l'Industrie, agit à titre de conseil technique permanent auprès du ministère du Travail dans toutes les questions qui relèvent de sa compétence. 